\title{
Annunciation Under Erasure
}

And he came to her and said

The Lord is

$$
\begin{aligned}
& \text { troubled } \\
& \text { in mind }
\end{aligned}
$$

The Holy

be afraid Mary
will overshadow you
therefore

be

nothing be impossible

And Mary said

And the angel departed from her 